Alaska Division of Geological \& Geophysical Surveys

RAW DATA FILE 2017-3

\title{
2017 DATA STEWARDSHIP SURVEY RESULTS
}

by

Jennifer E. Athey

$\$ 1.00$

May 2017

THIS REPORT HAS NOT BEEN REVIEWED FOR TECHNICAL CONTENT OR FOR CONFORMITY TO THE EDITORIAL STANDARDS OF DGGS

Released by

STATE OF ALASKA DEPARTMENT OF NATURAL RESOURCES

Division of Geological \& Geophysical Surveys

3354 College Road

Fairbanks, Alaska 99709-3707

907-451-5010

dggs.alaska.gov 


\title{
2017 DATA STEWARDSHIP SURVEY RESULTS
}

\author{
by \\ Jennifer E. Athey ${ }^{1}$

\section{INTRODUCTION}

Digital Mapping Techniques (DMT) is a workshop series hosted by the U.S. Geological Survey and the American Association of State Geologists. The workshop brings together scientists, cartographers, and GIS specialists, from State and Federal agencies, as well as Universities, the private sector, and international colleagues. In February 2017, the DMT-Sponsored Data Stewardship Committee conducted a voluntary survey of state geological surveys and other organizations that manage geological data. The Alaska Geological \& Geophysical Surveys (DGGS) volunteered to make the survey results available to the public. With the exception of identifying contact information, this RDF publication reports the raw results of the survey. All files can be downloaded from the DGGS website (http://doi.org/10.14509/29726).

\section{BACKGROUND}

At the three most recent Digital Mapping Techniques meetings (2014-2016), discussion sessions on information management (both digital and hard-copy media) and the stewardship of that information were held. As a result of those lively and enthusiastic discussions, attendees resolved to form a DMTSponsored Data Stewardship Committee, whose responsibility is to develop a report to inform agency managers of challenges and benefits of data stewardship and a set of technical resources to support said stewardship. The committee designed the 2017 Data Stewardship Survey to help define the contents of the report and technical guidance documents. Products of the Data Stewardship Initiative will be a report, providing data stewardship examples, guidance documents, and other information hosted on the DMT website (https://ngmdb.usgs.gov/Info/dmt/).

Members of the Data Stewardship Committee, in alphabetical order:

- Jennifer Athey, Alaska Division of Geological \& Geophysical Surveys

- Seth Bassett, Florida Geological Survey

- Rick Green, Florida Geological Survey

- Stephanie O'Meara, Colorado State University/Cooperator to the National Park Service

- Sarah Nagorsen, U.S. Geological Survey

- William "Sandy" Schenck, Delaware Geological Survey

- David Soller, U.S. Geological Survey

- Frederic "Ric" Wilson, U.S. Geological Survey

- Mark Yacucci, Illinois State Geological Survey

${ }^{1}$ Alaska Division of Geological \& Geophysical Surveys, 3354 College Road, Fairbanks, Alaska 99709-3707 


\section{METHODS}

The Data Stewardship Committee conducted the survey from January 30, 2017 through March 1, 2017 via SurveyMonkey. Ten multi-part questions addressed four main topics. With the exception of contact and organization information, questions and responses are presented in the accompanying spreadsheet file.

The purpose of and scope of each question:

\section{Contact and organization information.}

Fields collected include name, work phone, email address, job title, organization name, location of organization headquarters, and number of employees working at the organization. Only the number of employees working at the organization was included in this data release.

\section{Information about data stewardship at the organization.}

Questions focused on the general state and methodologies of data stewardship and preservation in the geologic community, such as the amounts and kinds of materials and data managed. Because every organization conducts data stewardship differently, this information provided the DMT-sponsored Data Stewardship Committee a broad understanding of the geologic community's data stewardship strengths and needs.

\section{Outcomes of (not) preserving data.}

One goal of the DMT-sponsored Data Stewardship Initiative is to provide organization leaders with a relatively brief report on the benefits of data stewardship, written by their staff and colleagues. This report supports resource allocation to conduct and (or) complete data stewardship work. The committee intended to solicit examples (i.e., stories) from the geologic community of the positive and negative consequences of various data stewardship scenarios, which may be particularly compelling for administrators and senior staff.

\section{Technical guidance in geologic data stewardship.}

Another goal of the Data Stewardship Initiative is to create online technical guidance regarding stewardship of geologic data. The questions on this topic addressed which types of information are most critical to organizations and requested examples of technical guidance that can be shared with the geologic community.

\section{DEFINITIONS}

Terms used throughout the survey, and how the committee defined them:

\section{Data stewardship}

"Data stewardship is the management and oversight of an organization's data assets [from acquisition to destruction], to help provide users with high-quality data that [are] easily accessible and usable in a consistent manner" http://searchdatamanagement.techtarget.com/definition/data-stewardship. Data stewardship includes the management and oversight of data preservation and archiving activities. 


\section{Preservation/Preserved}

As a general term, without specific regard to information management, defined as "to keep safe from injury, harm, or destruction" (https://www.merriam-webster.com/dictionary/preserve).

\section{Data preservation}

With the preface of "data," data preservation generally connotes preservation of digital data only (http://ifdo.org/wordpress/preservation/); however, we broaden it to include information in all formats (e.g., paper, film). In that context, it is a set of activities that ensures access to information for the foreseeable future (https://en.wikipedia.org/wiki/Preservation_(library_and_archival_science)).

\section{Archiving}

The action of collecting and managing a set of paper and (or) digital "records that have been selected for permanent or long-term preservation," on the basis of their historical or scientific value (https://en.wikipedia.org/wiki/Archive). This term is sometimes used synonymously with "preservation;" however, record accessibility is not necessarily addressed through the archiving process. Therefore, the term has more of a record "storage" connotation.

\section{Repository}

A central place where data are stored and maintained for the long term. Data repositories encourage data discovery, access, and potential reuse (https://www2.usgs.gov/datamanagement/preserve/ repositories.php).

\section{RESULTS}

The survey received 60 responses, 37 of which contained publishable information. Although the accompanying spreadsheet file has been edited for punctuation, spelling, and grammar, every effort was made to preserve the original sentiments of the survey responses. References to specific organizations, programs, and geographic locations were removed to preserve the anonymity of the respondents. 